\title{
A Global Stem Cell Niche - Need of the Hour
}

The time, this issue is online, most of us would be aware of the world's first induced pluripotent stem (iPS) cell based clinical trial for age-related macular degeneration which is underway in Japan. The first patient in the trial has been transplanted with the cell sheets of retinal pigment epithelium derived from the patient's own iPS cells in September 2014 ${ }^{[1]}$ and is under follow-up. As we are overwhelmed with this scientific feat, an analysis of the trends of stem cell based clinical trials globally ${ }^{[2]}$ makes us realize that there is a wide variation in the clinical trials between the nations, with differences being observed in diseases that are given priority, cell sources that are being chosen, principles of ethics, regulatory frameworks etc,. A realization dawns that the scientific communities in each group or country have their own niche of cell based research leading to the above mentioned variations.

While in Japan, a hi-tech iPS trial has started, Mazini et al from Morocco, describe the hurdles in creating a public cord blood bank in their country with a background of the regulatory guidelines existing there while Lee et als work from the United States of America (USA) focuses on microencapsulation of adipose derived stem cells. While each of the above subject are equally important, a global consortium is the need of the hour, where interactions among all the stake holders of cell based therapies can be established for enabling exchange of information, technology, solutions and products, thereby avoiding repetition of the same work, while gaining the insight of different viewpoints into solving an issue which could be of significance either to a local community or the entire global society.

\section{References}

1. Reardon S, Cyranoski D. Japan stem-cell trial stirs envy. Nature. 2014;513(7518):287-8.

2. Li MD, Atkins H, Bubela T. The global landscape of stem cell clinical trials. Regen Med. 2014 9(1):27-39. 